\title{
1 Amino acids substitutions in $\sigma 1$ and $\mu 1$ outer capsid proteins of a Vero cell-adapted \\ 2 mammalian orthoreovirus are required for optimal virus binding and disassembly
}

\section{Véronique Sandekian and Guy Lemay*}

5

Département de microbiologie, infectiologie et immunologie, Université de Montréal, Montréal, Canada H3C 3J7

7

8

$9 \quad$ *Corresponding author: Tel: +1 5143432422

Running title: Reovirus adaptation to Vero cells 


\section{ABSTRACT}

2 In a recent study, the serotype 3 Dearing strain of mammalian orthoreovirus was adapted to Vero cells; cells that exhibit a

3 limited ability to support the early steps of reovirus uncoating and are unable to produce interferon as an antiviral response

4 upon infection. The Vero cell-adapted virus (VeroAV) exhibits amino acids substitutions in both the $\sigma 1$ and $\mu 1$ outer capsid

5 proteins but no changes in the $\sigma 3$ protein. Accordingly, the virus was shown not to behave as a classical uncoating mutant.

6 In the present study, an increased ability of the virus to bind at the Vero cell surface was observed and is likely associated

7 with an increased ability to bind onto cell-surface sialic acid residues. In addition, the kinetics of $\mu 1$ disassembly from the

8 virions appears to be altered. The plasmid-based reverse genetics approach confirmed the importance of $\sigma 1$ amino acids

9 substitutions in VeroAV's ability to efficiently infect Vero cells, although $\mu 1$ co-adaptation appears necessary to optimize

10 viral infection. This approach of combining in vitro selection of reoviruses with reverse genetics to identify pertinent amino

11 acids substitutions appears promising in the context of eventual reovirus modification to increase its potential as an

12 oncolytic virus.

13

14 Keywords: Reovirus; Mutants; Binding; Uncoating; Sigma1; Mu1 


\section{Introduction}

(1)

(

Mammalian orthoreoviruses, hereafter referred to as "reovirus", are prototype members of the Orthoreovirus genus in the Reoviridae family. These viruses are generally cytolytic as they kill and lyse infected cells in culture; this has been generally attributed to apoptosis (reviewed in: Clarke et al., 2005; Danthi et al., 2010), although both necrotic (Berger and Danthi, 2013) and autophagic (Thirukkumaran et al., 2013) cell death likely occurs in certain cell types.

In the last few years, there has been renewed interest in the study of these viruses, given their ability to discriminate between normal and transformed/cancer cells, specifically infecting and killing the latter and giving rise to the idea of using them as "oncolytic viruses". This has led to numerous clinical studies as reviewed by others (Black and Morris, 2012; Clements et al., 2014; Harrington et al., 2010; Kelly et al., 2009; Maitra et al., 2012). Despite the fact that reoviruses are naturally oncolytic without prior genetic modifications, there is still a significant research effort ongoing to obtain novel virus variants better adapted to infect, replicate in, and kill cancer cells while sparing non-transformed cells (van den Hengel et al., 2013; Kim et al., 2011; Rudd and Lemay, 2005; Shmulevitz et al., 2012; van den Wollenberg et al., 2009 , 2012). One possible approach is to take advantage of novel viral variants that could be selected during establishment of viral persistence in different cell types.

Although reoviruses are considered to be essentially cytolytic, there have been numerous reports of persistence establishment with these viruses upon long-term cultivation of infected cells (reviewed in: Dermody, 1998). Since constant viral reinfection is needed to maintain the infected state, this has led to the identification of viral mutants, but few of those have been well characterized. In the most-studied L929 cell model, various amino acid substitutions were found in the viral $\sigma 1$ protein and a single amino acid substitution in $\sigma 3(\mathrm{Y} 354 \mathrm{H})$; both proteins being part of the outer capsid of the virion. The $\sigma 3-\mathrm{Y} 354 \mathrm{H}$ substitution was later shown to be most important for the ability of the virus to be maintained in persistently infected cells (Baer and Dermody, 1997; Ebert et al., 2001; Wetzel et al., 1997; Wilson et al., 2002). This amino acid substitution is located at the surface-exposed lobe of the $\sigma 3$ outer capsid protein, thus increasing the protein's sensitivity to proteases and favoring viral uncoating under conditions where proteases are present in limiting amount (Baer and Dermody, 1997; Wetzel et al., 1997). In more recent studies, amino acid substitutions in $\sigma 3$ were again observed in viruses recovered from Raji, HT1080 and CA46 cells, at positions consistent with an increased uncoating of these viruses; substitutions in $\sigma 1$ were also found in two of these viruses (Kim et al., 2011).

In the most recent study on reovirus persistence (Jabre et al., 2013), a novel variant of reovirus serotype 3 Dearing 
1 (T3/Human/Ohio/Dearing/55), named Vero cell-adapted virus (VeroAV) was obtained by long-term culture of the virus on

2 these cells that were previously shown to be somewhat resistant to a wild-type virus, due to their reduced ability to uncoat

3 the virus (Golden et al., 2002). Prior treatment with chymotrypsin, uncoating virions to "infectious subviral particles"

4 (ISVPs), significantly augmented infection by a wild-type virus while VeroAV exhibits an increased ability to infect Vero

5 cells even in the absence of prior uncoating by chymotrypsin treatment. Surprisingly, VeroAV did not behave as an

6 uncoating mutant, still showing normal sensitivity to inhibitors of lysosomal cathepsins, in contrast with uncoating mutants

7 selected during viral persistence in L929 cells (Baer and Dermody, 1997; Wilson et al., 2002). Accordingly, VeroAV does

8 not harbor amino acid substitutions in its $\sigma 3$ protein (Jabre et al., 2013). However, two amino acids substitutions

9 were found in each of the $\sigma 1$ and $\mu 1$ outer capsid proteins (Jabre et al., 2013), at positions consistent

10 with an altered binding to host cell surface or outer capsid disassembly (Reiter et al., 2011; Zhang et

11 al., 2005), but this was not further studied at the time.

The $\sigma 1$ protein forms the surface-exposed spikes at the surface of the virion and binds to both sialic acid and the

13 JAM receptor at the cell surface (Danthi et al., 2010; Dermody et al., 2013), $\sigma 1$ is also retained in infectious subviral

14 particles (ISVPs) that are generated by proteolytic cleavage of the outer capsid proteins; in fact, reovirus uncoating has been

15 shown to increase the binding of the resulting ISVPs to the cell surface (Chappell et al., 1998; Nibert et al., 1995). The

16 proteolytic cleavage of the outer capsid, referred to as "uncoating", takes place in endosomes following endocytosis of the

17 viral particles or in the extracellular milieu where proteases are present. Uncoating can also be achieved in the laboratory by

18 chymotrypsin treatment of virions and this facilitates infection of certain cell types, such as the Vero cells used in the

19 present study, that are inefficient in their ability to uncoat the virus (Golden et al., 2002). During uncoating, the $\sigma 3$ protein is

20 first removed, followed by proteolytic cleavage of the $\mu 1$ protein, allowing the viral particles to cross the cellular or

21 endosomal membrane (Danthi et al., 2010; Dermody et al., 2013). Together, the three outer capsid proteins $\sigma 1, \sigma 3$ and $\mu 1$,

22 are thus critical in infectivity of the viral particles and initiation of the viral replication cycle.

In the present study, the importance of the $\sigma 1$ and $\mu 1$ amino acid substitutions of VeroAV was thus further

24 examined. The virus was first shown to exhibit an increased binding at the surface of Vero cells likely due to an increased

25 binding to cell-surface sialic acid residues. An altered disassembly of its outer capsid, as evidenced by different kinetics of

26 in vitro cleavage by chymotrypsin, was also observed. The novel plasmid-based reverse genetics system (Kobayashi et al.,

27 2007, 2010; reviewed in: Boehme et al., 2011; van den Hengel et al., 2013; Lemay, 2011) then allowed to establish that the 
preferential infection of Vero cells is actually due to the $\sigma 1$ amino acid substitutions, although the co-adaptation of $\mu 1$

2 appears necessary to optimize viral infection. Altogether, these results indicate that the establishment of viral persistence can

3 select for different viral variants depending on the cell type. Combined with the analytical tool of reverse genetics, this

4 could allow for the optimization of selective reovirus infection of different cell types.

\section{2. Material and Methods}

8

9 2.1. Cell lines and viruses Biomedicals Inc. cells.

\subsection{Antibodies}

L929, HeLa and Vero cells were originally obtained from the American type culture collection (ATCC); the BHK cells stably expressing the T7 RNA polymerase have been described (Buchholz et al., 1999) and were a generous gift from the laboratory of Dr John Hiscott (Lady Davis Research Institute, Montréal, Canada). All cells were grown in minimal Eagle medium (MEM) with 5\% fetal bovine serum. Wild-type reovirus laboratory stock $\left(\mathrm{T} 3 \mathrm{D}^{\mathrm{S}}\right)$ was derived from a pure plaque of reovirus type 3 Dearing (T3/Human/Ohio/Dearing/55) and propagated at low multiplicity of infection on L929 cells. The original inoculum was obtained from the American Type Culture Collection (ATCC). Vero cell-adapted reovirus (VeroAV) was obtained following long-term culture of the wild-type virus on Vero cells (Jabre et al., 2013) and propagated on HeLa

Hybridoma cell lines producing either anti- $\sigma 3$ (4F2) or anti- $\mu 1$ (10F6) have been described (Virgin et al., 1991) and were obtained from Dr Kevin Coombs (University of Manitoba). Cells were grown in MEM for suspension culture with $10 \%$ fetal bovine serum, proline $(20 \mu \mathrm{g} / \mathrm{ml})$ and $\beta$-mercaptoethanol $(50 \mu \mathrm{M})$ and antibodies were recovered, as previously described (Brochu-Lafontaine and Lemay, 2012). The polyclonal antiserum directed against the carboxyl-terminal head domain of $\sigma 1$ was produced originally in the laboratory of Dr. Terence Dermody (Vanderbilt University, Tennessee) and was a generous gift from Dr. Earl Brown (University of Ottawa). The rabbit anti-tubulin antiserum was obtained from ICN 
Virus titers were determined by TCID 50 method on L929 cells in 96-wells plates (Danis and Lemay, 1993). For electron microscopy, infectious virus stocks were extracted once with Vertrel ${ }^{\circledR}$ XF $(1,1,1,2,3,4,4,5,5,5$-decafluoropentane;

4 Miller-Stephenson Chemical company Inc.) (Mendez et al., 2000) to remove most cellular debris and mixed with latex 5 beads at a known concentration. Processing of samples and microscopic observations were done at the INRS-Institut 6 Armand Frappier (Laval, Québec) electron microscopy facilities.

7

\subsection{Virus binding at the host-cell surface}

Infectious viral particles at a MOI of $80 \mathrm{PFU} /$ cell were allowed to bind onto the host-cell surface of L929 or Vero cells for one hour at $4^{\circ} \mathrm{C}$ with occasional gentle agitation. Cells with bound virions were then extensively washed with cold medium and immediately frozen at $-80^{\circ} \mathrm{C}$ for virus titration. In some experiments, neuraminidase (from Clostridium perfringens, New England Biolabs) pretreatment was done at $37^{\circ} \mathrm{C}$ at a concentration of 50 units $/ \mathrm{ml}$ in tissue culture medium for one hour. Neuraminidase was then removed, cells were washed with medium, and binding of virions at $4^{\circ} \mathrm{C}$ was performed, as before.

\subsection{In vitro cleavage of capsid proteins with chymotrypsin}

Virions prepared by Vertrel extraction of viral stocks (propagated in the absence of serum) were incubated from 0 to 30 minutes at 10 or $40 \mu \mathrm{g} / \mathrm{ml}$ concentrations of chymotrypsin at $37^{\circ} \mathrm{C}$ or $28^{\circ} \mathrm{C}$. Reactions were stopped by addition of 2 mM phenylmethylsulfonyl fluoride (PMSF) and samples were analyzed by immunoblotting using either the combination of anti- $\mu 1$ and anti- $\sigma 3$ monoclonal antibodies or the anti- $\sigma 1$ polyclonal antiserum.

\subsection{Immunoblotting}

Infected cells were recovered by scraping in a small volume of medium and processed for immunoblotting, as previously described (Brochu-Lafontaine and Lemay, 2012). Images were obtained using either autoradiography on Kodak BioMax Light films or on a Typhoon Trio ${ }^{\mathrm{TM}}$ imager (GE Healthcare Life Sciences).

\subsection{Plasmid constructs}

The plasmids separately harboring each of the cDNA corresponding to the 10 genes of reovirus serotype 3 Dearing 
$1 \quad\left(\mathrm{~T}_{3} \mathrm{D}^{\mathrm{K}}\right)$, under the transcriptional control of the $\mathrm{T} 7$ promoter, were previously described (Kobayashi et al., 2007) and were a

2 generous gift from the laboratory of Dr Terence Dermody (Vanderbilt University, Nashville, Tennessee). To obtain the virus

3 mutant harboring the amino acids substitutions of VeroAV in the defined background of the reverse genetics system, a

4 fragment of the gene encompassing all mutations was obtained by RT-PCR amplification on the viral VeroAV genome,

5 essentially as previously described (Brochu-Lafontaine and Lemay, 2012; Jabre et al., 2013). PCR fragments were

6 recovered and subcloned to replace the corresponding fragment in the M2 or S1 reverse genetics plasmid. A similar strategy

7 was used to construct a wild-type plasmid corresponding to the initial wild-type laboratory virus stock (T3D $\left.{ }^{\mathrm{S}}\right)$.

9 2.8. Rescue of infectious mutant viruses by reverse genetics

Small-scale preparations of endotoxin-free plasmid DNA, corresponding to the different M2 and S1 genes were

11 column-purified as recommended by the manufacturer (Zyppy plasmid miniprep kit, Zymo Research). Recovery of

12 infectious reovirus stocks by transfection of the baby hamster kidney (BHK) cell line constitutively expressing the T7 RNA

13 polymerase (Buchholz et al., 1999) was done essentially as previously described (Brochu-Lafontaine and Lemay, 2012).

14 The presence of the expected amino acid substitutions and absence of other mutations on the three genes encoding outer capsid proteins was verified by RT-PCR and sequencing of the corresponding fragment, as for the original VeroAV (Jabre et

16

17

18

19

20

21

22

23

24 al., 2013).

\subsection{Plaque assay}

Plaque assays were performed on Vero cells in the presence of chymotrypsin (Sigma Type I-S from bovine pancreas) at 5 $\mu \mathrm{g} / \mathrm{ml}$, as previously described (Brochu-Lafontaine and Lemay, 2012; Jabre et al., 2013).

\section{Results}

\subsection{Binding of reovirus VeroAV at the cell surface}

Considering the position of the amino acids substitutions on both $\sigma 1$ and $\mu 1$ of VeroAV, it was previously suggested that virus disassembly and/or binding could be affected by these changes (Jabre et al., 2013). This last point was first examined as a possible explanation for the increased ability of VeroAV to infect Vero cells.

Infectious virus stocks of either VeroAV or the original wild-type laboratory virus stock from which it was 
originally derived were thus prepared by infection of HeLa cells; this wild-type virus will be referred to as type 3 Dearing,

2 isolate Sandekian $\left(\mathrm{T}^{2} \mathrm{D}^{\mathrm{S}}\right.$ ) to distinguish it from other stocks of wild-type virus, as will be discussed later in the manuscript.

3 VeroAV and $\mathrm{T}_{3} \mathrm{D}^{\mathrm{S}}$ virus stocks were first compared to determine if they exhibit a similar particle/infectious titer ratio. The

4 presence of similar numbers of $\mathrm{T}^{\mathrm{S}} \mathrm{D}^{\mathrm{S}}$ and VeroAV viral particles for the same viral titer was confirmed by quantitative

5 electron microscopy using a latex bead standard (data not shown). Although somewhat variable from one preparation to

6 another, the ratio of the number of virus particles to viral infectivity titer was approximately 100 particles/PFU for both

7 viruses. This is, in fact, quite similar to previous reports by other groups (Bokiej and Dermody, 2012; Doyle et al., 2012;

8 Frierson et al., 2012; Hand and Tamm, 1973; Mendez et al., 2000).

9 To directly determine their binding to the cell surface, virions were then adsorbed onto the cells In a preliminary

10 experiment, binding of the $\mathrm{T}_{3} \mathrm{D}^{\mathrm{S}}$ virus was shown to increase linearly at all MOI tested, up to 250 (data

11 not shown). This is not surprising considering that binding assay are routinely performed at 50,000

12 particles per cell by other investigators (for example Bokiej and Dermody, 2012). An intermediate MOI

13 of 80 was thus used thereafter to avoid saturation of the cellular receptors. In these conditions, $\mathrm{T}^{\mathrm{D}} \mathrm{D}^{\mathrm{S}}$

14 bound to both L929 and Vero cells with essentially the same efficiency whereas the VeroAV virions showed more than

15 fivefold increase in binding to Vero cells compared to the $\mathrm{T}^{\mathrm{N}} \mathrm{D}^{\mathrm{S}}$ virions (Fig. 1). Although VeroAV virions also apparently

16 bind slightly better to the L929 cell surface, this difference was not statistically significant. The data rather indicate that the

17 increase in binding of VeroAV at the cell surface results from an adaption to binding preferentially onto these cells.

18

19

\subsection{Binding of wild-type $T 3 D^{S}$ and VeroAV virions to sialic acids}

Considering the position of the amino acid substitutions observed in $\sigma 1$ of VeroAV (Table I), compared with wildtype $\mathrm{T}^{\mathrm{S}} \mathrm{D}^{\mathrm{S}}$ and wild-type reverse genetics virus (T3D-Kobayashi, $\mathrm{T} 3 \mathrm{D}^{\mathrm{K}}$ ), an increased binding of the virions to sialic acids at the cell surface was postulated. Amino acid 198 is part of the sialic acid binding region of the protein, and is known to somehow contribute to the sialic binding property of the protein (Chappell et al., 1997; Dermody et al., 1990), although it does not appear to directly interact with the sugar moieties (Reiter et al., 2011).

In a preliminary experiment, the hemagglutination potential of VeroAV was examined as a first indication of binding to sialic acid (Chappell et al., 1997; Dermody et al., 1990). Semi-purified viral particles from either T3D ${ }^{\mathrm{S}}$ or VeroAV were submitted to serial twofold dilutions and their ability to agglutinate bovine red blood cells was compared. At the 
1 concentrations used, hemagglutination could not be detected with the semi-purified $\mathrm{T}_{3} \mathrm{D}^{\mathrm{S}}$ virions while, at the same protein

2 concentration, hemagglutination was observed up to the $4^{\text {th }}$ binary dilution with VeroAV. In this assay, when compared with

3 cesium chloride-purified $\mathrm{T} 3 \mathrm{D}^{\mathrm{S}}$ virions, the hemagglutination potential of VeroAV is thus at least 8-fold higher than that of

$4 \quad \mathrm{~T}^{\mathrm{S}} \mathrm{D}^{\mathrm{s}}$ (supplementary Fig. S1).

To further determine if the presence of sialic acid at the cell surface is involved in the increased binding of VeroAV to the surface of Vero cells, the cells were pre-treated with neuraminidase to remove cell surface sialic acids before virus

7 binding. In preliminary experiments, the concentration of 50 units/ml appeared as optimal to see an

8 effect on virus adsorption while minimizing host-cell toxicity (data not shown) this concentration was

9 thus retained as experimental conditions. Although not considered statistically significant, an almost

10 twofold increase in binding was found with $\mathrm{T}_{3} \mathrm{D}^{\mathrm{S}}$; this is somewhat reminiscent of the situation

11 observed with some "sialidase-insensitive" rotavirus strains (Haselhorst et al. 2009). This was not

12 further investigated but could be due to increased accessibility of other cellular receptors, either protein

13 such as the JAM receptor or other glycans, after terminal sialic acid removal by neuraminidase. In

14 contrast, there was an almost threefold decrease in binding for VeroAV under the same conditions (Fig. 2). Altogether these

15 results support the idea that increased binding of VeroAV at the surface of Vero cells depends on the presence of sialic acid

16 residues at the cell surface.

\subsection{Outer capsid disassembly of wild-type T3D ${ }^{S}$ and VeroAV virions}

Considering the position of amino acid substitutions on $\mu 1$, there is also a possibility that its cleavage and outer

20 capsid disassembly could be affected, as discussed previously (Jabre et al., 2013), and could thus affect the differential

21 infectivity of the virus in the presence or absence of prior chymotrypsin treatment. To directly examine this possibility,

22 virions were treated with $10 \mu \mathrm{g} / \mathrm{ml}$ chymotrypsin in vitro for different times. As expected, removal of $\sigma 3$ was observed for

23 both $\mathrm{T}_{3} \mathrm{D}^{\mathrm{S}}$ and VeroAV, although apparently less efficiently for VeroAV. However, a striking difference was observed for $\mu 1$

24 that was gradually converted from $\mu 1 \mathrm{C}$ to $\delta$ for $\mathrm{T}^{\mathrm{S}} \mathrm{D}^{\mathrm{S}}$ while $\mu 1 \mathrm{C}$ of VeroAV gradually disappeared without concomitant

25 accumulation of $\delta$ protein (Fig. 3, upper panel).

This kinetics of $\mathrm{T}^{\mathrm{D}} \mathrm{D}^{\mathrm{s}}$ disassembly is similar to that previously reported for serotype 1 Lang virus (T1L), while that 
1 protein of $\mathrm{T}_{3} \mathrm{D}^{\mathrm{S}}$ harbors a valine at position 305 , as in $\mathrm{T} 1 \mathrm{~L}$, while an alanine is found in other isolates of $\mathrm{T} 3 \mathrm{D}$ such as $\mathrm{T} 3 \mathrm{D}^{\mathrm{K}}$

2 (Table I). This difference between T3D ${ }^{\mathrm{K}}$ and T1L is responsible for their different disassembly kinetics (Madren et al.,

3 2012). In contrast, although it harbors a valine at position 305 , VeroAV behaves as $\mathrm{T}_{3} \mathrm{D}^{\mathrm{K}}$; this is most likely due to the

4 additional amino acid substitutions at positions 89 and/or 114 (Jabre et al., 2013). Interestingly, while we were completing

5 this work, it has been further established that the loop comprising amino acids 72 to 96 of $\mu 1$ is involved in stability of the

6 outer capsid and affects its disassembly upon protease treatment. It is especially striking that glutamic acid 89 was found to

7 be the most critical amino acid in this phenotype (Sarkar and Danthi, 2013).

The amount of $\sigma 1$ in the viral particles during gradual disassembly was also examined by immunoblotting. There

9 was no apparent difference in the stability of the protein in the viral capsid during disassembly (Fig. 3, lower panel);

10 however, a significantly higher amount of $\sigma 1$ was found in VeroAV virions compared to $\mathrm{T}^{\mathrm{S}} \mathrm{D}^{\mathrm{S}}$ virions; as estimated by the

11 ratio of $\sigma 1$ to $\sigma 3$ signal, there appears to be approximately three times more $\sigma 1$ per viral particle for VeroAV compared to the

$12 \mathrm{~T} 3 \mathrm{D}^{\mathrm{s}}$ virions, raising the possibility that the amount of $\sigma 1$ in the viral particle, in addition to a difference in affinity for

13 sialic acids, could be responsible for increased virus binding at the cell surface.

14

15

16

17

18

19

\subsection{Rescue of virus mutants using plasmid-based reverse genetics}

To confirm that the amino acid substitutions in $\sigma 1$ and $\mu 1$ are responsible for T3D adaptation to Vero cells and to explore whether amino acid substitutions on both proteins are required, the fragments encompassing the substitutions of VeroAV compared to $\mathrm{T}_{3} \mathrm{D}^{\mathrm{S}}$ were obtained by RT-PCR on the viral genomic dsRNA and used to substitute the homologous fragment in the corresponding gene of $\mathrm{T} 3 \mathrm{D}^{\mathrm{K}}$ used for plasmid-based reverse genetics (Kobayashi et al., 2007).

These plasmid constructs could then be used to generate a mutant virus harboring the amino acid substitutions of VeroAV $\sigma 1$ (protein referred hereafter as $\sigma 1-\mathrm{AV}$ ), including those differences between $\mathrm{T}^{\mathrm{S}} \mathrm{D}^{\mathrm{S}}$ and $\mathrm{T} 3 \mathrm{D}^{\mathrm{K}}$ that are also present in the same fragment. In parallel, the same procedure was applied to generate a plasmid harboring solely the three amino acid differences between $\mathrm{T} 3 \mathrm{D}^{\mathrm{S}}$ and $\mathrm{T} 3 \mathrm{D}^{\mathrm{K}}$ in this protein (proteins referred hereafter as $\sigma 1-\mathrm{S}$ and $\sigma 1-\mathrm{K}$, respectively), in order to generate a control virus in a $\mathrm{T}^{\mathrm{K}} \mathrm{D}^{\mathrm{K}}$ background for all other viral proteins. A similar procedure was used for the $\mathrm{M} 2$ gene to introduce the fragment encompassing all amino acids changes on $\mu 1$ of VeroAV, including differences between $\mathrm{T} 3 \mathrm{D}^{\mathrm{S}}$ and $\mathrm{T} 3 \mathrm{D}^{\mathrm{K}}$ (protein hereafter referred to as $\mu 1-\mathrm{AV}$ ). These two amino acid differences between $\mathrm{T} 3 \mathrm{D}^{\mathrm{S}}$ and $\mathrm{T} 3 \mathrm{D}^{\mathrm{K}}$ were introduced in a separate plasmid to generate a control virus harboring the $\mu 1$ protein of T3D $\mathrm{D}^{\mathrm{S}}$ (hereafter referred to as $\mu 1-\mathrm{S}$ ) in a wild-type $\mathrm{T} 3 \mathrm{D}^{\mathrm{K}}$ background. The amino acid differences between $\mathrm{T}^{\mathrm{K}} \mathrm{D}^{\mathrm{K}}, \mathrm{T}_{3} \mathrm{D}^{\mathrm{S}}$ and VeroAV in both $\sigma 1$ and $\mu 1$ proteins 
are summarized in Table I.

The different plasmids were then used in the plasmid-based reverse genetics system to rescue viruses harboring amino acid substitutions in either $\sigma 1, \mu 1$ or both, in an otherwise wild-type $\mathrm{T}^{\mathrm{N}} \mathrm{D}^{\mathrm{K}}$ background. All viruses were propagated before sequencing of the complete genes encoding $\sigma 1, \sigma 3$ and $\mu 1$ of the final virus stocks to confirm that they possessed the expected sequences.

For some viruses, the titers obtained upon viral propagation remained very low (Fig. 4).

Interestingly, it appears that viruses produced with $\mu 1-\mathrm{K}$ had higher titers than those with either $\mu 1-\mathrm{S}$ or $\mu 1-\mathrm{AV}$ except for the $\sigma 1-\mathrm{AV} / \mu 1-\mathrm{AV}$ combination. The worst combination was that of $\sigma 1-\mathrm{AV} / \mu 1-\mathrm{S}$, strongly suggesting that $\mu 1-\mathrm{S}$ had to evolve concomitantly with $\sigma 1-\mathrm{AV}$ during selection of VeroAV.

\subsection{Infectivity of rescued viruses in Vero cells}

The different viruses were then analyzed for their relative ability to infect Vero cells in the presence or absence of chymotrypsin in a single-cycle assay using immunoblotting. Two viruses, presenting poorly adapted protein combinations ( $\sigma 1-\mathrm{K}$ with $\mu 1-\mathrm{AV}$ and $\sigma 1-\mathrm{AV}$ with $\mu 1-\mathrm{S}$ ), and whose titers were reduced more than a thousandfold, were not examined. As expected, viruses harboring either $\sigma 1-\mathrm{S} / \mu 1-\mathrm{S}$ or $\sigma 1-\mathrm{K} / \mu 1-\mathrm{K}$ wild-type combinations were poorly infectious on Vero cells in the absence of chymotrypsin while their infectivity was increased upon chymotrypsin treatment (Fig. 5), as with the original wild-type $\mathrm{T}_{3} \mathrm{D}^{\mathrm{S}}$ virus. The combination $\sigma 1-\mathrm{AV} / \mu 1-\mathrm{AV}$ resulted in a virus that was able to infect Vero cells independently of the presence of chymotrypsin, with even a small reduction in its presence, similar to the parental VeroAV. The two proteins are thus solely responsible for the adaptation of VeroAV to better infect Vero cells.

The $\sigma 1-\mathrm{AV}$ protein VeroAV combined with $\mu 1-\mathrm{K}$ did confer by itself an ability to promote infection of Vero cells in the absence of chymotrypsin. In contrast $\mu 1-\mathrm{AV}$ by itself had no effect when combined with $\sigma 1-\mathrm{S}$. Altogether, these data indicate that amino acid substitutions in $\sigma 1-\mathrm{AV}$ are the primary determinants of the increased ability of VeroAV to infect Vero cells as virions. However, the nature of the $\mu 1$ protein is also of importance to optimize virus infection. While the $\sigma 1-\mathrm{AV} / \mu 1-\mathrm{S}$ virus could not be further studied, the $\sigma 1-\mathrm{AV} / \mu 1-\mathrm{K}$ virus was still partly dependent on prior chymotrypsin treatment to infect Vero cells (Fig. 5), indicating that $\mu 1$-AV contributes to overall viral fitness but may also affect the ability of $\sigma 1$-AV to promote infection of Vero cells. 
In contrast to the predominant effect of $\sigma 1-\mathrm{AV}$ on infection of Vero cells, the $\mu 1-\mathrm{AV}$ protein appears to be

2 essentially responsible for increased sensitivity to chymotrypsin resulting in smaller plaques (Table II). As previously

3 illustrated (Jabre et al., 2013), wild-type plaques are approximately 0.7 to $1 \mathrm{~mm}$ in diameter under the conditions used while

4 VeroAV plaques are mostly punctate and less than $0.2 \mathrm{~mm}$ in diameter. The 4 different combinations of $\mathrm{T}_{3} \mathrm{D}^{\mathrm{S}}$ and $\mathrm{T}_{3} \mathrm{D}^{\mathrm{K}}$

5 proteins did not yield plaque sizes that were significantly different from wild-type while the introduction of both $\sigma 1-\mathrm{AV}$ and

$6 \mu 1$-AV yielded plaques that were similar in size to that of the original VeroAV. However, the sole addition of $\mu 1-\mathrm{AV}$ to either

$7 \sigma 1-\mathrm{S}$ or $\sigma 1-\mathrm{K}$ resulted in a small-plaque phenotype suggesting that $\mu 1-\mathrm{AV}$ is responsible for this phenotype, as expected

8 from its altered kinetics of chymotrypsin cleavage in vitro in the original VeroAV. The exact contribution of $\sigma 1-\mathrm{AV}$ to this

9 phenotype was more difficult to assess since it was not fully compatible with other $\mu 1$ proteins. However, despite a lower

10 virus titer, plaques were still seen when $\sigma 1-\mathrm{AV}$ was combined with $\mu 1-\mathrm{K}$; their size was intermediate between that of T3D

11 and VeroAV plaques. The resistance $\sigma 1-\mathrm{AV}$ to in vitro chymotrypsin digestion of the parental VeroAV (as shown in Fig. 3,

12 lower panel) also supports the idea that it is not the principal determinant of chymotrypsin sensitivity or of altered virus

13 disassembly.

14

\subsection{Further characterization of rescued $T 3 D^{K}(\sigma 1-A V / \mu 1-A V)$}

The phenotypic properties of the rescued virus harboring either the $\sigma 1$ and $\mu 1$ protein of either $\mathrm{T}_{3} \mathrm{D}^{\mathrm{S}}$ or VeroAV in the $\mathrm{T}^{\mathrm{K}} \mathrm{D}^{\mathrm{K}}$ background were then further examined. First, the effect of neuraminidase treatment on binding to Vero cells was examined by comparing the original $\mathrm{T} 3 \mathrm{D}^{\mathrm{S}}$ and VeroAV with the rescued viruses, namely $\mathrm{T} 3 \mathrm{D}^{\mathrm{K}}(\sigma 1-\mathrm{AV} / \mu 1-\mathrm{AV})$ and $\mathrm{T} 3 \mathrm{D}^{\mathrm{K}}(\sigma 1-\mathrm{S} / \mu 1-\mathrm{S})$. The results confirmed that the presence of both $\sigma 1$ and $\mu 1$ of VeroAV increased sensitivity to neuraminidase treatment up to a level similar to that of the original VeroAV (Fig.6, panel A). However, the increased binding of $T 3 \mathrm{D}^{\mathrm{S}}$ observed upon neuraminidase treatment was not observed with $\mathrm{T} 3 \mathrm{D}^{\mathrm{K}}(\sigma 1-\mathrm{S} / \mu 1-\mathrm{S})$. This suggests that other differences between $\mathrm{T} 3 \mathrm{D}^{\mathrm{S}}$ and $\mathrm{T} 3 \mathrm{D}^{\mathrm{K}}$ do exist in other viral protein(s) and that they indirectly affect the phenotype of $\sigma 1$, as shown by others with amino acids substitutions in $\lambda 2$ (Shmulevitz et al. 2012).

The kinetics of in vitro proteolytic uncoating of the same two rescued viruses was then examined and compared with that of the original $\mathrm{T}^{\mathrm{S}} \mathrm{D}^{\mathrm{S}}$ and Vero $\mathrm{AV}$, as in figure 3 . This time, uncoating was examined at both $37^{\circ} \mathrm{C}$ and $28^{\circ} \mathrm{C}$, as described (Sarkar and Danthi, 2013). Removal of $\sigma 3$ was less efficient for $\mathrm{T}_{3} \mathrm{D}^{\mathrm{K}}(\sigma 1-\mathrm{AV} / \mu 1-\mathrm{AV})$ than for $\mathrm{T} 3 \mathrm{D}^{\mathrm{K}}(\sigma 1-\mathrm{S} / \mu 1-\mathrm{S})$, as with the original viruses (Fig. 6 , panel 
1 B), and this was better evidenced at the lower temperature; this indicates that the different kinetics of

2 uncoating was maintained in the rescued viruses. More importantly, T3D ${ }^{\mathrm{K}}(\sigma 1-\mathrm{S} / \mu 1-\mathrm{S})$ showed an

3 almost complete conversion of $\mu 1 \mathrm{C}$ to $\delta$ at $37^{\circ} \mathrm{C}$, as expected, while in $\mathrm{T}^{2} \mathrm{D}^{\mathrm{K}}(\sigma 1-\mathrm{AV} / \mu 1-\mathrm{AV})$ there was

4 a decline of $\mu 1 \mathrm{C}$ without concomitant accumulation of $\delta$. Again, the phenotype of $\mathrm{T}_{3} \mathrm{D}^{\mathrm{K}}(\sigma 1-\mathrm{AV} / \mu 1-$

5 AV) was thus essentially the same as that of the original VeroAV, in which $\delta$ is rapidly removed from

6 ISVPs in the presence of proteases, and the wild-type $T 3 \mathrm{D}^{\mathrm{K}}(\sigma 1-\mathrm{S} / \mu 1-\mathrm{S})$ behaves as the original $\mathrm{T} \mathrm{D}^{\mathrm{S}}$

7 virus.

8 Finally, immunoblotting was performed on viral particles for some of these viruses whose titers

9 were sufficiently high (Fig. 7). It was found that both the sequence of $\sigma 1$ and $\mu 1$ affected the amount of

10 virion-associated $\sigma 1$. Virions corresponding to plasmid-rescued VeroAV T3D $(\sigma 1-\mathrm{AV} / \mu 1-\mathrm{AV})$ harbor

11 more $\sigma 1$ relative to $\sigma 3$ than virions from plasmid-rescued $\mathrm{T}_{3} \mathrm{D}^{\mathrm{K}}(\sigma 1-\mathrm{S} / \mu 1-\mathrm{S})$, as observed with the

12 original viruses presented on the right panel, as a control. This also corresponds to the previous

13 observation at time 0 on Fig. 3. However, $\mu 1-\mathrm{K}$ was able to increase the amount of both $\sigma 1-\mathrm{S}$ and $\sigma 1-$

$14 \mathrm{AV}$ in the virion despite the fact that $\mathrm{T}_{3} \mathrm{D}^{\mathrm{K}}$ itself harbors a low amount of $\sigma 1$. This again indicates that a

15 compatibility between $\mu 1$ and $\sigma 1$ is needed to optimize both the incorporation and function of $\sigma 1$ in the

16 viral particles. However, there was no apparent relation between the number of $\sigma 1$ molecules

17 incorporated to the virion and either the ability to infect Vero cells (Fig. 5) or the replicative ability of

18 these viruses on HeLa cells used for viral propagation (Fig. 4).

\section{4. Discussion}

As with most viruses, the replicative ability of mammalian reoviruses has been mostly examined in few cell types.

24 In the last few years, renewed interest in oncolytic reovirus replication has led to the realization that the nature of the host 
1 cells could restrict viral infection and lead, in return, to virus adaptation. In a previous work (Jabre et al., 2013), Vero cells

2 were chosen as a model; these cells are also classically used to grow viruses for clinical applications (Berry et al., 1999;

3 World Health Organization, 1987) and are deficient in interferon production (Desmyter et al., 1968; Emeny and Morgan,

4 1979), thus facilitating large-scale production of interferon-sensitive viruses.

5 Surprisingly, virus persistence of reovirus in Vero cells did not give rise to a virus with an

6 increased ability to be uncoated by lower amount of lysosomal cathepsins following viral endocytosis

7 (Jabre et al., 2013). Accordingly, the $\sigma 3$ protein, known as the major determinant of reovirus uncoating

8 efficiency was left unaltered in VeroAV. However, the other two other outer capsid proteins, $\sigma 1$ and $\mu 1$,

9 respectively responsible for earlier step of virus binding at the host cell surface and later step of viral

10 disassembly, were both exhibiting amino acids substitutions. Although the position of the substitutions

11 lead to speculate about a possible alteration of virus binding and/or later disassembly steps (Jabre et al.

12 2013), there was no experimental evidence to support this idea. In the present study, the virus was

13 further studied by the new tools of plasmid-based reverse genetics in order to introduce the VeroAV

14 amino acids substitutions in a wild-type virus background. These studies allowed to firmly establish

15 that the $\sigma 1$ and $\mu 1$ amino acids substitutions are solely responsible for the ability of VeroAV to infect

16 Vero cells in the absence of prior uncoating while giving rise to viruses that are more readily

17 inactivated upon prolonged protease treatment. The increased ability to infect Vero cells was assigned

18 essentially to an increased binding to sialic acids, as previously hypothesized (Jabre et al. 2013);

19 however, a very interesting point is the apparent co-evolution between $\sigma 1$ and $\mu 1$, suggesting that these

20 two proteins need to be well-adapted to each other in order to optimize viral fitness.

If binding at the cell surface is critical to the efficient infection of Vero cells by VeroAV, it may appear surprising

22 that the wild-type viruses can attach at similar levels on L929 and Vero cells; however, this is consistent with previous

23 observations showing that binding of wild-type ISVPs is not increased compared to virions on Vero cells, despite the

24 increase in infection (Golden et al., 2002). It is possible that the increased binding of VeroAV virions rather contributes to

25 facilitate later entry steps, normally bypassed in ISVPs. Asparagine 198 was previously shown to be involved in $\sigma 1$ binding 
1 to sugars containing sialic acid (Chappell et al., 1997; Dermody et al., 1990; Reiter et al., 2011), although crystallographic

2 analysis failed to reveal a direct interaction between this amino acid residue and the sugar moieties (Reiter et al., 2011). In

3 these studies, replacing the uncharged asparagine by an acidic amino acid (aspartic acid) was shown to preclude sialic acid

4 binding. Reciprocally, in VeroAV, replacing asparagine by a basic amino acid (lysine) increases sialic acid binding. The

5 observation that N198K was already found early in the process of viral adaptation (Jabre et al., 2013) pleads in favor of its

6 prominent role in the phenotype on Vero cells. However, the virus harboring solely this substitution was only partially able

7 to bypass the restriction in Vero cells and still exhibited reduced infectivity (data not shown), indicating that later amino

8 acids substitutions were required to achieve optimal infection as in VeroAV. Furthermore, it cannot be excluded that some

9 other changes were later selected due to gradual virus-cell coevolution, as observed during reovirus persistence of various

10 cell types (reviewed by: Dermody, 1998).

Unexpectedly, an approximately threefold increase in the amount of $\sigma 1$ in VeroAV virions compared to the wild-

12 type was observed in the course of this work, and was shown to depend on both the nature of the $\sigma 1$ and $\mu 1$ proteins.

13 However, the increased amount of $\sigma 1$ per se does not increase infectivity on Vero cells in the absence of adequate amino

14 acid substitutions. It has been reported that some reovirus strains such as type 3 Dearing harbors an average of

15 approximately 18 trimers of $\sigma 1$ per particle while type 1 Lang harbors a full complement of 36 trimers (Coombs, 1998 ;

16 Larson et al., 1994); considering the relative difficulty of precisely comparing these results, they appear consistent with a

17 threefold increase in the amount of $\sigma 1$ that was observed in VeroAV, rendering it similar to T1L with probably the highest

18 possible number of $\sigma 1$ trimers. It is interesting to note that reducing trimers to only three copies does not seem to affect

19 infectivity, at least in L929 cells (Larson et al., 1994); the lack of effect on viral infectivity on Vero cells when the number

20 of wild-type $\sigma 1$ trimers increased is also consistent with this idea. Interestingly, an approximately 3 -fold difference in $\sigma 1$

21 incorporation between two viral clones of reovirus type 3 Dearing was also recently reported (Nygaard et al., 2013) and

22 attributed to an amino acid substitution in the virion-anchoring region of $\sigma 1$. In VeroAV, the substitution at position 78 is

23 outside the critical 28 amino acid amino-terminal anchoring region; although it cannot be excluded that this substitution in

24 the adjacent region may influence incorporation (Leone et al., 1991). The exact significance of these variations in the

25 amount of virion-incorporated $\sigma 1$, if any, remains to be established but is likely due to differences in the structural stability

26 of the capsid (Coombs, 1998). This is also supported by the observation that the loss of $\sigma 1$ upon long-term storage of the

27 virion at $4^{\circ} \mathrm{C}$ is more drastic in strains that already have a lower amount of $\sigma 1$ per virion (Nygaard et al., 2013).

Although the amino acid substitutions in $\mu 1$ do not appear to be directly involved in the ability of VeroAV to infect 
1 Vero cells, the nature of the $\mu 1$ protein does affect viral replication per se and ability to infect Vero cells in the presence of

2 the $\sigma 1$ protein of VeroAV. The apparent co-evolution of $\sigma 1$ and $\mu 1$ suggests that these two proteins need to be

3 well-adapted to each other in order to optimize viral fitness. Similar observations were previously made in

4 different contexts such as the determinants of apoptosis or neurovirulence (Clarke et al., 2001; Derrien et al., 2003; Hrdy et

5 al., 1982; Rodgers et al., 1997; Tyler et al., 1996). These $\mu 1$ changes selected in VeroAV were probably necessary due to the

6 nature of the $\mu 1$ protein in the initial wild-type virus $\left(\mathrm{T}_{3} \mathrm{D}^{\mathrm{S}}\right)$ since other $\mu 1$ sequences such as that of T3D $\mathrm{D}^{\mathrm{K}}$ are also able,

7 although not as efficiently, to accommodate the $\sigma 1$ protein of VeroAV. As previously discussed (Jabre et al., 2013), the

8 contact regions between $\mu 1$ in neighboring heterohexamers are similar to the contact regions between $\mu 1$ and the $\lambda 2$ turret

9 protein suggesting that amino acids at this interface, such as amino acid 89 , could affect association or exposure of $\sigma 1$ at the

10 virion's surface (Liemann et al., 2002; Zhang et al., 2005; Middleton et al., 2007). The data presented herein give

11 further support to the idea that these two proteins functionally interact.

The presence of a valine at position 305 of $\mu 1$ in both $\mathrm{T}^{\mathrm{S}} \mathrm{D}$ and VeroAV also deserves to be further stressed; as

13 previously noted, most isolates of mammalian reoviruses harbor a valine while an alanine is found in some virus stocks such

14 as $\mathrm{T}^{\mathrm{K}} \mathrm{D}^{\mathrm{K}}$. This amino acid was recently shown to affect autocleavage and viral disassembly (Madren et al., 2012; Sarkar and

15 Danthi, 2010) and this difference could explain why the reverse genetics viruses harboring the $\mu 1-\mathrm{K}$ protein are able to

16 promote infection in the absence of chymotrypsin when combined with the $\sigma 1-\mathrm{AV}$ protein while the original $\mu 1-\mathrm{S}$ is not.

17 Thus, there is clearly an influence of the original sequence of the virus on the final result obtained upon viral adaptation to a

18 given cell line. Although it is difficult to predict how a virus having a different $\mu 1$, such as T3D ${ }^{\mathrm{K}}$, would have evolved under

19 the same conditions, it is likely that either $\sigma 1$ alone or $\sigma 1$ and $\mu 1$ would have adapted to Vero cells since $\mathrm{T} 3 \mathrm{D}^{\mathrm{K}}$ virions infect

20 these cells poorly.

21 In the present and previous manuscript (Jabre et al., 2013), Vero cells were used to demonstrate

22 that it is possible to generate novel reoviruses that are adapted to different cell lines and that this does

23 not solely rely on the ability of the virus to be uncoated, as in the classical L929 cells model. These

24 proof of concept experiments suggest that it should be also possible to adapt the virus to different cell

25 types in order to further optimize reovirus oncolytic ability. This idea has been previously suggested

26 and, accordingly, novel viruses were found to be better adapted as oncolytic agents (Kim et al., 2011; 
1 Rudd et al., 2005; Shmulevitz et al., 2012; van den Wollenberg et al., 2012). Viruses selected for their

2 large-plaque phenotype using L929 cells, somewhat reminiscent of larger plaques formed by VeroAV

3 on Vero cells in the absence of chymotrypsin, were shown to be better oncolytic viruses both in vitro

4 and in animal models (Shmulevitz et al., 2012). A recent report (van den Wollenberg et al., 2012) also

5 suggests that the ability to infect cells independently of the JAM receptor, possibly due to increased

6 binding to sialic acids, could be a useful strategy against cancer cell types that express low levels of

7 JAM and are thus relatively resistant to reovirus (van den Hengel et al., 2013; van den Wollenberg et

8 al., 2009; van Houdt et al., 2008). Furthermore, a virus harboring a deletion of the JAM binding

9 domain and binding solely onto cell surface sialic acids, was shown to be attenuated in nontransformed

10 cells while retaining an oncolytic potential and exhibiting reduced host toxicity (Kim et al., 2011).

11 Although there is no evidence yet that VeroAV has a superior oncolytic activity, it will thus be of

12 interest to further study its ability to lyse tumor cells in tissue culture and eventually in animal models.

13 Novel variant viruses, such as VeroAV, combined with the use of reverse genetics could allow the

14 design of superior oncolytic agents while getting fundamental knowledge on the viral and cellular

15 factors that determine a successful reovirus infection.

\section{Acknowledgments}

21 Institute, Montreal, Canada) for the initial stock of BHK cells expressing the T7 RNA polymerase, Dr Kevin Coombs

22 (University of Manitoba) for the hybridoma cells producing antireovirus monoclonal antibodies and Dr Earl G. Brown

23 (Ottawa University) for the anti- $\sigma 1$ polyclonal antiserum originally obtained from Dr Terence Dermody (Vanderbilt

24 University). We thank Miguel Chagnon (Département de Mathématiques et Statistiques, Université de Montréal) for his

25 help with statistical analysis and interpretation. 
2 Canada (NSERC) to G.L. We thank the "Faculté des études supérieures et postdoctorales" of the "Université de Montréal" 3 for partial financial support to V.S.

4 We thank Roland Jabre for numerous helpful discussions and Dr George Szatmari (Université de Montréal) for 5 critical reading and very helpful suggestions to improve the manuscript. 


\section{References}

2

3

Baer, G.S., Dermody, T.S., 1997. Mutations in reovirus outer-capsid protein sigma3 selected during persistent infections of L cells confer resistance to protease inhibitor E64. J. Virol. 71, 4921-4928.

Berger, A.K., Danthi, P., 2013. Reovirus activates a caspase-independent cell death pathway. MBio 4, e00178.

Berry, J.M., Barnabé, N., Coombs, K.M., Butler, M., 1999. Production of reovirus type-1 and type-3 from Vero cells grown on solid and macroporous microcarriers. Biotechnol. Bioeng. 62, 12-19.

Black, A.J., Morris, D.G., 2012. Clinical trials involving the oncolytic virus, reovirus: Ready for prime time? Expert Rev. Clin. Pharmacol. 5, 517-520.

Boehme, K.W., Ikizler, M., Kobayashi, T., Dermody, T.S., 2011. Reverse genetics for mammalian reovirus. Methods 55, 109113.

Bokiej, M., Dermody, T.S., 2012. Optimum length and flexibility of reovirus attachment protein sigma1 are required for efficient viral infection. J. Virol. 19, 10270-10280.

Brochu-Lafontaine, V., Lemay, G., 2012. Addition of exogenous polypeptides on the mammalian reovirus outer capsid using reverse genetics. J. Virol. Methods 179, 342-350.

Buchholz, U.J., Finke, S., Conzelmann, K.K., 1999. Generation of bovine respiratory syncytial virus (BRSV) from cDNA: BRSV NS2 is not essential for virus replication in tissue culture, and the human RSV leader region acts as a functional BRSV genome promoter. J. Virol. 73, 251-259.

Chappell, J.D., Gunn, V.L., Wetzel, J.D., Baer, G.S., Dermody, T.S., 1997. Mutations in type 3 reovirus that determine binding to sialic acid are contained in the fibrous tail domain of viral attachment protein $\sigma 1$. J. Virol. 71, 18341841.

Chappell, J.D., Barton, E.S., Smith, T.H., Baer, G.S., Duong, D.T., Nibert, M.L., Dermody, T.S., 1998. Cleavage susceptibility of reovirus attachment protein sigma1 during proteolytic disassembly of virions is determined by a sequence polymorphism in the sigma1 neck. J. Virol. 72, 8205-8213.

Clarke, P., Meintzer, S.M., Widmann, C., Johnson, G.L., Tyler, T.S., 2001. Reovirus infection activates JNK and the JNKdependent transcription factor c-Jun. J. Virol. 75, 11275-11283.

Clarke, P., Richardson-Burns, S.M., DeBiasi, R.L., Tyler, K.L., 2005. Mechanisms of apoptosis during reovirus infection. Curr. Top. Microbiol. Immunol. 289, 1-24. 
1 Clements, D., Helson, E., Gujar, S.A., Lee, P.W.K., 2014. Reovirus in cancer therapy: an evidencebased review. Oncolytic Virother. 3, 69-82.

3 Coombs, K.M., 1998. Stoichiometry of reovirus structural proteins in virus, ISVP, and core particles. Virology 243, 218228.

Danis, C., Lemay, G., 1993. Protein synthesis in different cell lines infected with orthoreovirus serotype 3: inhibition of host-cell protein synthesis correlates with accelerated viral multiplication and cell killing. Biochem. Cell Biol. 71, $81-85$.

Danthi, P., Guglielmi, K.M., Kirchner, E., Mainou, B., Stehle, T., Dermody, T.S., 2010. From touchdown to transcription: the reovirus cell entry pathway. Curr. Top. Microbiol. Immunol. 343, 91-119.

Dermody, T.S., Nibert, M.L., Bassel-Duby, R., Fields, B.N., 1990. A $\sigma 1$ region important for hemagglutination by serotype 3 reovirus strains. J. Virol. 64, 5173-5176.

Dermody, T.S., 1998. Molecular mechanisms of persistent infection by reovirus. Curr. Top. Microbiol. Immunol. 233, 1-22.

Dermody, T.S., Parker, J.S.L., Sherry, B., 2013. Orthoreoviruses, in: Knipe, D.M., Howley, P.M., (Eds.), Fields Virology, $6^{\text {th }}$ Edition. Lippincott, Williams \& Wilkins, Philadephia, U.S.A., pp. 1305-1391.

Derrien, M., Hooper, J.W., Fields, B.N., 2003. The M2 gene segment is involved in the capacity of reovirus type 3 Abney to induce the oily fur syndrome in neonatal mice, a S1 gene segment-associated phenotype. Virology 305, 25-30.

Desmyter, J., Melnick, J.L., Rawls, W.E., 1968. Defectiveness of interferon production and of rubella virus interference in a line of African green monkey kidney cells (Vero). J. Virol. 2, 955-961.

Doyle, J.D., Danthi, P., Kendall, E.A., Ooms, L.S., Wetzel, J.D., Dermody, T.S., 2012. Molecular determinants of proteolytic disassembly of the reovirus outer capsid. J. Biol. Chem. 287, 8029-8038.

Ebert, D.H., Wetzel, J.D., Brumbaugh, D.E., Chance, S.R., Stobie, L.E., Baer, G.S., Dermody, T.S., 2001. Adaptation of reovirus to growth in the presence of protease inhibitor E64 segregates with a mutation in the carboxy terminus of viral outer-capsid protein sigma3. J. Virol. 75, 3197-3206.

Emeny, J.M., Morgan, M.J., 1979. Regulation of the interferon system: evidence that Vero cells have a genetic defect in interferon production. J. Gen. Virol. 43, 247-252.

Frierson, J.M., Pruijssers, A.J., Konopka, J.L., Reiter, D.M., Abel, T.W., Stehle, T., Dermody, T.S., 2012. Utilization of sialylated glycans as coreceptors enhances the neurovirulence of serotype 3 reovirus. J. Virol. 86, 13164-13173.

Golden, J.W., Linke, J., Schmechel, S., Thoemke, K., Schiff, L.A., 2002. Addition of exogenous protease facilitates reovirus 
infection in many restrictive cells. J. Virol. 76, 7430-7443.

Hand, R., Tamm, I., 1973. Reovirus: effect of noninfective viral components on cellular deoxyribonucleic acid synthesis. J. Virol. 11, 223-231.

Harrington, K.J., Vile, R.G., Melcher, A., Chester, J., Pandha, H.S., 2010. Clinical trials with oncolytic reovirus: Moving beyond phase I into combinations with standard therapeutics. Cytokine Growth Factor Rev. 21, 91-98.

Haselhorst, T., Fleming, F.E., Dyason, J.C., Hartnell, R.D., Yu, X., Holloway, G., Santegoets, K., Kiefel, M.J., Blanchard, H., Coulson, B.S., von Itzstein, M., 2009. Sialic acid dependence in rotavirus host cell invasion. Nat. Chem. Biol. 5, 91-93.

Hrdy, D.B., Rubin, D.H., Fields, B.N., 1982. Molecular basis of reovirus neurovirulence: role of the M2 gene in avirulence. Proc. Natl. Acad. Sci. U.S.A. 79, 1298-1302.

Jabre, R., Sandekian, V., Lemay, G., 2013. Amino acid substitutions in $\sigma 1$ and $\mu 1$ outer capsid proteins are selected during mammalian reovirus adaptation to Vero cells. Virus Res. 176, 188-198.

Kelly, K., Nawrocki, S., Mita, A., Coffey, M., Giles, F.J., Mita, M., 2009. Reovirus-based therapy for cancer. Expert Opin. Biol. Ther. 9, 817-830.

Kim, M., Garant, K.A., zur Nieden, N.I., Alain, T., Loken, S.D., Urbanski, S.J., Forsyth, P.A., Rancourt, D.E., Lee, P.W., Johnston, R.N., 2011. Attenuated reovirus displays oncolysis with reduced host toxicity. Br. J. Cancer 104, 290 299.

Kobayashi, T., Antar, A.A., Boehme, K.W., Danthi, P., Eby, E.A., Guglielmi, K.M., Holm, G.H., Johnson, E.M., Maginnis, M.S., Naik, S., Skelton, W.B., Wetzel, J.D., Wilson, G.J., Chappell, J.D., Dermody, T.S., 2007. A plasmid-based reverse genetics system for animal double-stranded RNA viruses. Cell Host Microbe 1, 147-157.

Kobayashi, T., Ooms, L.S., Ikizler, M., Chappell, J.D., Dermody, T.S., 2010. An improved reverse genetics system for mammalian orthoreoviruses. Virology 398, 194-200.

Larson, S.M., Antczak, J.B., Joklik, W.K., 1994. Reovirus exists in the form of 13 particle species that differ in their content of protein sigma1. Virology 201, 303-311.

Lemay, G., 2011. La génétique inverse dans l'étude des réovirus : progrès, obstacles et développements futurs [Reverse genetics in the study of reoviruses: progress, obstacles and future developments] Virologie 15, 53-62 [in French]. 
Leone, G., Mah, D.C., Lee, P.W., 1991. The incorporation of reovirus cell attachment protein sigma 1 into virions requires the N-terminal hydrophobic tail and the adjacent heptad repeat region. Virology 182, 346-350.

Liemann, S., Chandran, K., Baker, T.S., Nibert, M.L., Harrison, S.C., 2002. Structure of the reovirus membrane-penetration protein, Mu1, in a complex with is protector protein, Sigma3. Cell 108, 283-295.

Madren, J.A., Sarkar, P., Danthi, P., 2012. Cell entry-associated conformational changes in reovirus particles are controlled by host protease activity. J. Virol. 86, 3466-3473.

Maitra, R., Ghalib, M.H., Goel, S., 2012. Reovirus: a targeted therapeutic - progress and potential. Mol. Cancer Res. 10, $1514-1525$.

Mendez, I.I., Hermann, L.L., Hazelton, P.R., Coombs, K.M., 2000. A comparative analysis of freon substitutes in the purification of reovirus and calicivirus. J. Virol. Methods 90, 59-67.

Middleton, J.K., Agosto, M.A., Severson, T.F., Yin, J., Nibert, M.L., 2007. Thermostabilizing mutations in reovirus outercapsid protein mu1 selected by heat inactivation of infectious subvirion particles. Virology 361, 412-425.

Nibert, M.L., Chappell, J.D., Dermody, T.S., 1995. Infectious subvirion particles of reovirus type 3 Dearing exhibit a loss in infectivity and contain a cleaved sigma 1 protein. J. Virol. 69, 5057-5067.

Nygaard, R.M., Lahti, L., Boehme, K.W., Ikizler, M., Doyle, J.D., Dermody, T.S., Schiff, L.A., 2013. Genetic determinants of reovirus pathogenesis in a murine model of respiratory infection. J. Virol. 87, 9279-9289.

Reiter, D.M., Frierson, J.M., Halvorson, E.E., Kobayashi, T., Dermody, T.S., Stehle, T., 2011. Crystal structure of reovirus attachment protein $\sigma 1$ in complex with sialylated oligosaccharides. PLoS Pathog. 7, e1002166.

Rodgers, S.E., Barton, E.S., Oberhaus, S.M., Pike, B., Gibson, C.A., Tyler, K.L., Dermody, T.S., 1997. Reovirus-induced apoptosis of MDCK cells is not linked to viral yield and is blocked by Bcl-2. J. Virol. 71, 2540-2546.

Rudd, P., Lemay, G., 2005. Correlation between interferon sensitivity of reovirus isolates and ability to discriminate between normal and Ras-transformed cells. J. Gen. Virol. 86, 1489-1497.

Sarkar, P., Danthi, P., 2010. Determinants of strain-specific differences in efficiency of reovirus entry. J. Virol. 84, 1272312732.

Sarkar, P., Danthi, P., 2013. The mu1 72-96 loop controls conformational transitions during reovirus cell entry. J. Virol. 87, $13532-13542$.

Shmulevitz, M., Gujar, S.A., Ahn, D.G., Mohamed, A., Lee, P.W.K., 2012. Reovirus variants with mutations in S1 and L2 genome segments exhibit enhanced virion infectivity and superior oncolysis. J. Virol. 86, 7403-7413. 
Thirukkumaran, C.M., Shi, Z.Q., Luider, J., Kopciuk, K., Gao, H., Bahlis, N., Neri, P., Pho, M., Stewart, D., Mansoor, A., Morris, D.G., 2013. Reovirus modulates autophagy during oncolysis of multiple myeloma. Autophagy 9, 59-58. Tyler, K.L., Squier, M.K.T., Brown, A.L., Pike, B., Willis, D., Oberhaus, S.M., Dermody, T.S., Cohen, J., 1996. Linkage between reovirus-induced apoptosis and inhibition of cellular DNA synthesis: role of the S1 and M2 genes. J. Virol. 70, 7984-7991.

van den Hengel, S.K., Dautzenberg I.J.C., van den Wollenberg, D.J.M., Sillevis Smitt, P.A.E., Hoeben, R.C., 2013. Genetic modification in mammalian orthoreoviruses, in: Bridgen, A., (Ed.), Reverse genetics of RNA viruses: Applications and perspectives. John Wiley \& Sons Ltd., Chichester, West Sussex, UK, pp. 289-317.

van den Wollenberg, D.J., Van Den Hengel, S.K., Dautzenberg, I.J., Kranenburg, O., Hoeben, R.C., 2009. Modification of mammalian reoviruses for use as oncolytic agents. Expert Opin. Biol. Ther. 9, 1509-1520.

van den Wollenberg, D.J.M., Dautzenberg, I.J.C., van den Hengel, S.K., Cramer, S.J., de Groot, R.J., Hoeben, R.C., 2012. Isolation of reovirus T3D mutants capable of infecting human tumor cells independent of junction adhesion molecule-A. PLoS One 7, e48064.

van Houdt, W.J., Smakman, N., van den Wollenberg, D.J.M., Emmink, B.L., Veenendaal, L.M., van Diest ,P.J., Hoeben, R.C., Borel Rinkes, I.H.M., Kranenburg, O., 2008. Transient infection of freshly isolated human colorectal tumor cells by reovirus T3D intermediate subviral particles. Cancer Gene Ther. 15, 284-292.

Virgin, H.W., Mann, M.A., Fields, B.N., Tyler, K.L., 1991. Monoclonal antibodies to reovirus reveal structure/function relationships between capsid proteins and genetics of susceptibility to antibody action. J. Virol. 65, 6772-6781.

Wetzel, J.D., Wilson, G.J., Baer, G.S., Dunnigan, L.R., Wright, J.P., Tang, D.S., Dermody, T.S., 1997. Reovirus variants selected during persistent infections of L cells contain mutations in the viral S1 and S4 genes and are altered in viral disassembly. J. Virol. 71, 1362-1369.

Wilson, G.J., Nason, E.L., Hardy, C.S., Ebert, D.H., Wetzel, J.D., Venkataram Prasad, B.V., Dermody, T.S., 2002. A single mutation in the carboxy terminus of reovirus outer-capsid protein sigma 3 confers enhanced kinetics of sigma 3 proteolysis, resistance to inhibitors of viral disassembly, and alterations in sigma 3 structure. J. Virol. 76, 98329843.

World Health Organization., 1987. Requirements for continuous cell lines used for biological substances. World Health 
Organ. Tech. Rep. Ser. 745, 99-115.

2 Zhang, X., Ji, Y., Zhang, L., Harrison, S.C., Marinescu, D.C., Nibert, M.L., Baker, T.S., 2005. Features of reovirus outer 3 capsid protein mu1 revealed by electron cryomicroscopy and image reconstruction of the virion at 7.0 Angstrom resolution. Structure 13, 1545-1557. 


\section{Figure legends}

3 Fig. 1. Virus binding at the cell surface. Inoculum of $8 \times 10^{8} \mathrm{TCID}_{50}$ units of the original wild-type $\mathrm{T} 3 \mathrm{D}\left(\mathrm{T} 3 \mathrm{D}^{\mathrm{S}}\right)$ or of the

4 derived Vero cell-adapted virus (VeroAV) were adsorbed at the surface of either L929 or Vero cells at a multiplicity of

5 infection of $80 \mathrm{TCID}_{50}$ units/cell. Following binding for one hour at $4^{\circ} \mathrm{C}$, cells were washed and bound virus was quantitated

6 by $\mathrm{TCID}_{50}$ titration on L929 cells. Results are presented as the mean of 5 (L929 cells) and 8 (Vero cells) independent

7 binding experiments. Error bars represent standard error of the mean. P-value are based on a linear mixed-effects

8 model using a random intercept grouped by replica. N.S.: not statistically significant, $\mathrm{p}>0.05$

10 Fig. 2. Effect of sialic acid removal on virus binding. Vero cells were left untreated or pre-treated with neuraminidase,

11 before adsorption of $2 \times 10^{8} \mathrm{~T}^{\mathrm{S}} \mathrm{D}^{\mathrm{S}}$ or VeroAV virions and quantitation of bound virus, as in figure 1. Results are presented

12 as the mean of four independent binding experiments with error bars representing standard error of the mean. P-value are

13 based on a linear mixed-effects model using a random intercept grouped by replica. N.S.: not

14 statistically significant, $\mathrm{p}>0.05$

15

16

17

18

19

20

21

22 Fig. 4. Replicative ability of rescued viruses. HeLa cells were infected at a MOI of $2 \mathrm{TCID}_{50}$ units/cell and virus stocks

23 obtained by freeze-thaw lysate 48 hours post-infection. Virus titers were obtained by TCID $_{50}$ on L929 cells. Results are 
1 presented relative to the titer obtained with the $\mathrm{T}_{3} \mathrm{D}^{\mathrm{K}}(\sigma 1-\mathrm{S} / \mu 1-\mathrm{S})$ combination $\left(7 \mathrm{X} 10^{7} \mathrm{PFU} / \mathrm{ml}\right)$ that was arbitrarily fixed to 21

4 Fig. 5. Infection of Vero cells with rescued viruses. Viruses obtained by reverse genetics were used to infect Vero cells at a

5 MOI of 2 in the absence or presence of chymotrypsin, as indicated; L929 cells were used as control. Proteins were

6 recovered 24 hours post-infection and analyzed by immunoblotting using a combination of anti- $\sigma 3$ and anti- $\mu 1$ monoclonal

7 antibodies; positions of $\sigma 3$ and $\mu 1 \mathrm{C}$ are indicated. Lower panels present the same membrane that was re-probed with rabbit

8 anti-tubulin antiserum indicating similar amount of proteins in each lane. Infections with the original T3D $\mathrm{D}^{\mathrm{S}}$ and $\mathrm{VeroAV}$ are 9 presented as controls.

11 Fig. 6. Phenotypic properties of rescued $T 3 \mathrm{D}^{\mathrm{K}}(\sigma 1-\mathrm{AV} / \mu 1-\mathrm{AV})$. Vero cells were left untreated or pre-treated with 12 neuraminidase, as in figure 2 , before adsorption of $\mathrm{T}_{3} \mathrm{D}^{\mathrm{K}}$, VeroAV, rescued $\mathrm{T} 3 \mathrm{D}^{\mathrm{K}}(\sigma 1-\mathrm{S} / \mu 1-\mathrm{S})$ or rescued T3D $(\sigma 1-\mathrm{AV} / \mu 1-$ $13 \mathrm{AV}$ ) at a multiplicity of infection of $80 \mathrm{TCID}_{50}$ units/cell. Following binding for one hour at $4^{\circ} \mathrm{C}$, cells were washed and 14 bound virus was quantitated by TCID $_{50}$ titration on L929 cells, as in figure 1 and 2 . The average effect of neuraminidase in 15 two representative experiments is presented with error bars representing standard error of the mean (panel A). Virions from 16 original T3D $\mathrm{D}^{\mathrm{S}}$ and VeroAV (upper panel) or rescued $\mathrm{T} 3 \mathrm{D}^{\mathrm{K}}(\sigma 1-\mathrm{S} / \mu 1-\mathrm{S})$ and $\mathrm{T} 3 \mathrm{D}^{\mathrm{K}}(\sigma 1-\mathrm{AV} / \mu 1-\mathrm{AV})$ were extracted with 17 Vertrel $^{\mathrm{TM}}$ and treated for the indicated times at either $28^{\circ} \mathrm{C}$ or $37^{\circ} \mathrm{C}$ with chymotrypsin, a control reaction was left at $4^{\circ} \mathrm{C}$

18 (panel B). Reactions were stopped and proteins analyzed by immunoblotting using combination of anti- $\sigma 3$ and anti- $\mu 1$ 19 monoclonal antibodies. Positions of $\sigma 3$ and $\mu 1 \mathrm{C}$ and $\delta$ proteins are indicated by arrowheads.

21 Fig. 7. Amount of $\sigma 1$ in virions of rescued viruses. Infectious virus stocks were extracted once with Vertrel and proteins 22 analyzed by immunoblotting using a combination of anti- $\sigma 3$ and anti- $\mu 1$ monoclonal antibodies (upper panels) or the anti$23 \sigma 1$ polyclonal antiserum (lower panels); positions of $\sigma 3, \mu 1 \mathrm{C}$ and ${ }^{\circ} 1$ are indicated. The original $\mathrm{T} 3 \mathrm{D}^{\mathrm{S}}$ and $\mathrm{VeroAV}$ are 24 presented as controls. 


\section{Supplementary}

3

\section{Figure legend}

5

6

7 Fig. S1. Hemagglutination potential of VeroAV compared to the $\mathrm{T}^{\mathrm{S}} \mathrm{D}^{\mathrm{S}}$. Virus stocks were extracted once with Vertrel to

8 remove most of cellular debris and concentrated by ultrafiltration using Sartorius Vivaspin Turbo 15 centrifugal

9 concentrators (molecular weight cutoff of $1000 \mathrm{kDa}$ ). Serial binary dilution was done in tissue culture medium without

10 serum, starting from an initial titer of $2 \times 10^{9} \mathrm{TCID}_{50} \mathrm{units} / \mathrm{ml}$. As a control, cesium-chloride purified virus was first diluted

11 10-fold to reach an infectious titer of approximately $10^{10} \mathrm{TCID}_{50}$ units/ml and similarly subjected to serial binary dilution.

12 Fifty microliters of viruses at different dilutions were placed in round-bottom 96 -wells microplates. Washed $10 \%$ bovine red

13 blood cells (Cedarlane) were diluted to $1.5 \%$ in tissue culture medium and $50 \mu$ l were added to each well. Plates were

14 examined and photographed after 3 hours of incubation at $4^{\circ} \mathrm{C}$.

15 


\section{Table 1}

Table 1:

\begin{tabular}{|c|c|c|c|c|}
\hline \multirow{3}{*}{$\sigma 1$} & T3D $^{S}$ & T3D $^{K}$ & VeroAV & $\begin{array}{c}\text { Amino acid } \\
\text { position }\end{array}$ \\
\hline & $\mathbf{Q}$ & $\mathbf{Q}$ & $\mathbf{P}$ & 78 \\
\hline & $\mathbf{N}$ & $\mathbf{N}$ & $K$ & 198 \\
\hline \multirow{7}{*}{$\mu 1$} & I & $\mathbf{T}$ & I & 249 \\
\hline & s & $\mathbf{Y}$ & s & 253 \\
\hline & A & $T$ & A & 408 \\
\hline & E & E & G & 89 \\
\hline & A & A & V & 114 \\
\hline & v & A & V & 305 \\
\hline & $T$ & A & $T$ & 449 \\
\hline
\end{tabular}

Differences between the original reverse genetics wild-type clone $\mathrm{T} 3 \mathrm{D}^{\mathrm{K}}$ and both the laboratory wild-type virus stock $\mathrm{T} 3 \mathrm{D}^{\mathrm{S}}$ and VeroAV are indicated by light gray boxes. Substitutions unique to VeroAV are indicated by dark gray boxes. 


\section{Table 2}

Table 2:

\begin{tabular}{lccc}
\hline & $\sigma 1-\mathrm{S}$ & $\sigma 1-\mathrm{K}$ & $\sigma 1-\mathrm{AV}$ \\
\hline$\mu 1-\mathrm{S}$ & large & large & $(-)$ \\
$\mu 1-\mathrm{K}$ & large & large & reduced \\
$\mu 1-\mathrm{AV}$ & small & small & small \\
\hline
\end{tabular}

Plaque size of rescued viruses. Plaque assays were performed on Vero cells in the presence of chymotrypsin, as described in Materials and methods. Examination of representative plaques 4 days post-infection was done after staining and under an inverted microscope. Large and small plaques were previously illustrated (Jabre et al., 2013); reduced plaques have an intermediate phenotype while (-) indicates the lack of visible plaques. 
Figure 1

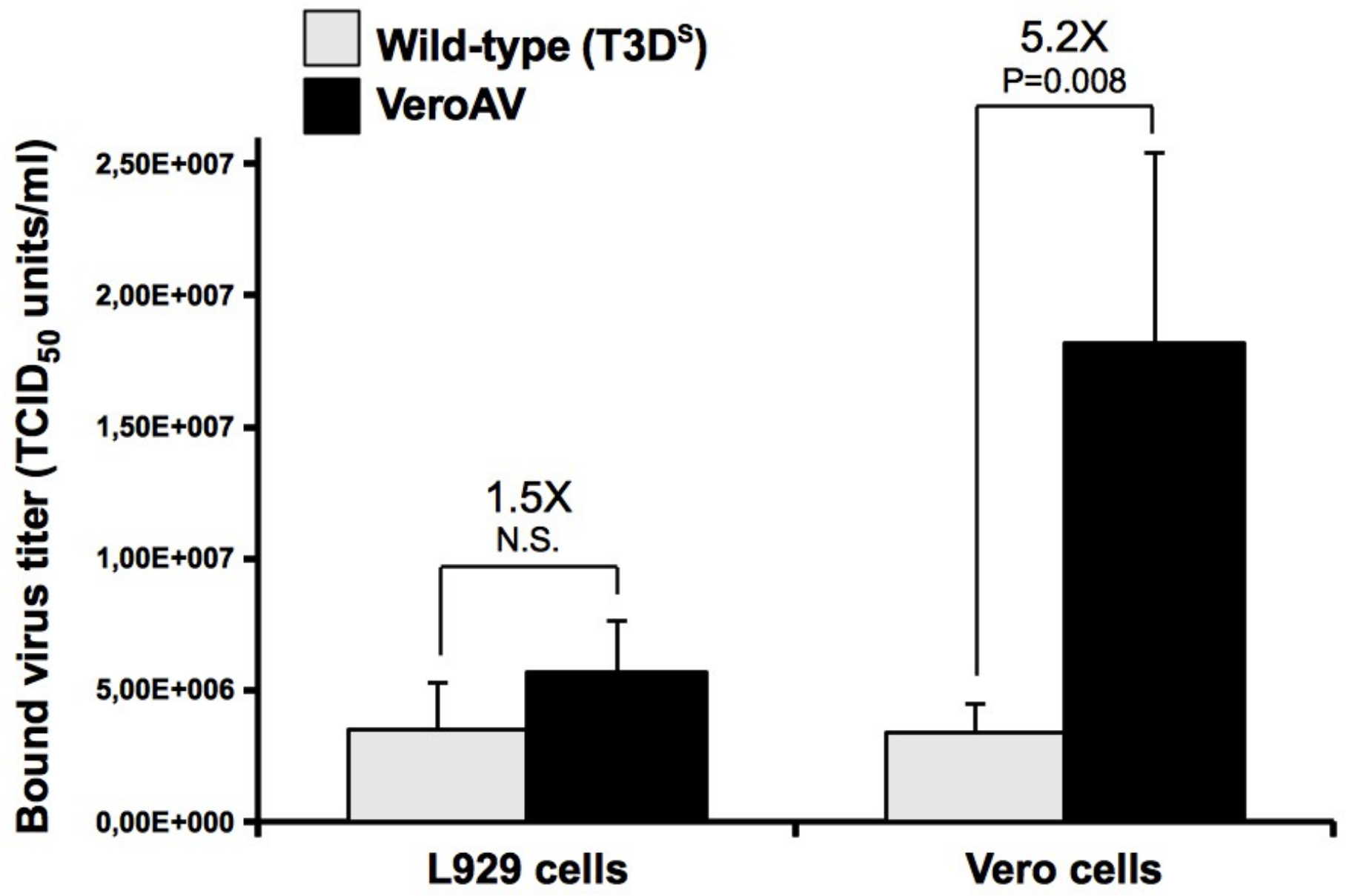


Figure 2

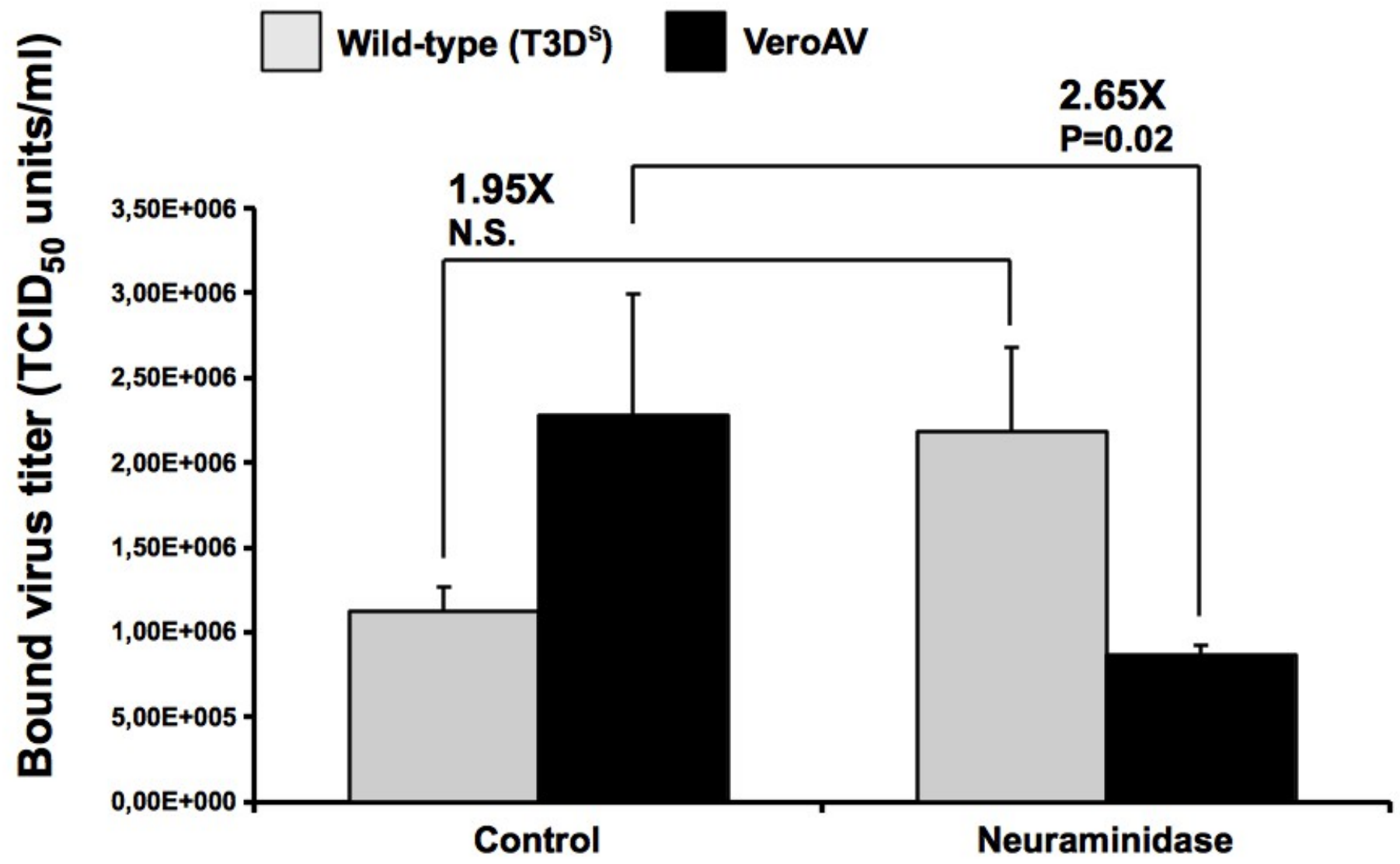


Figure 3

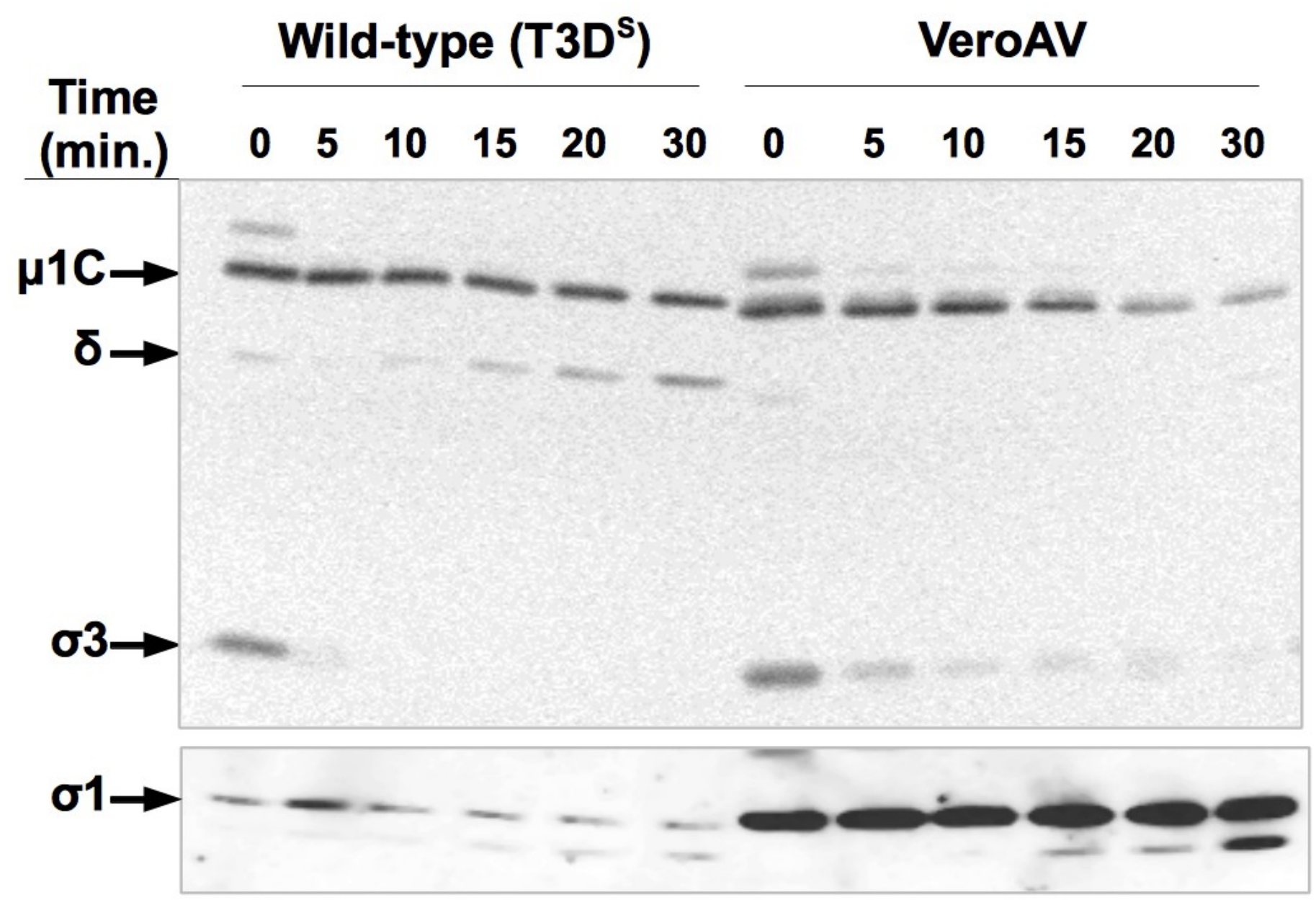


Figure 4

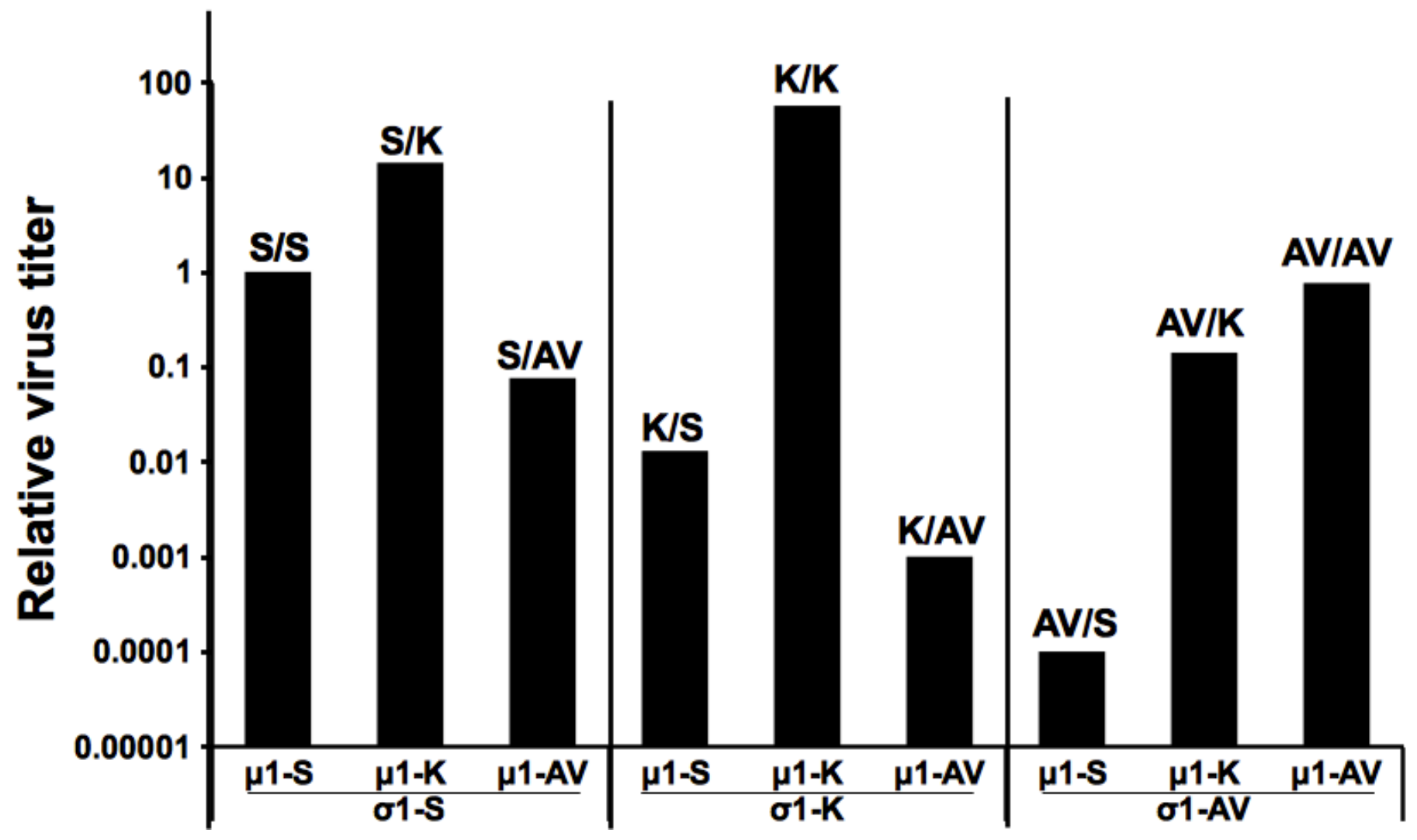


Figure 5

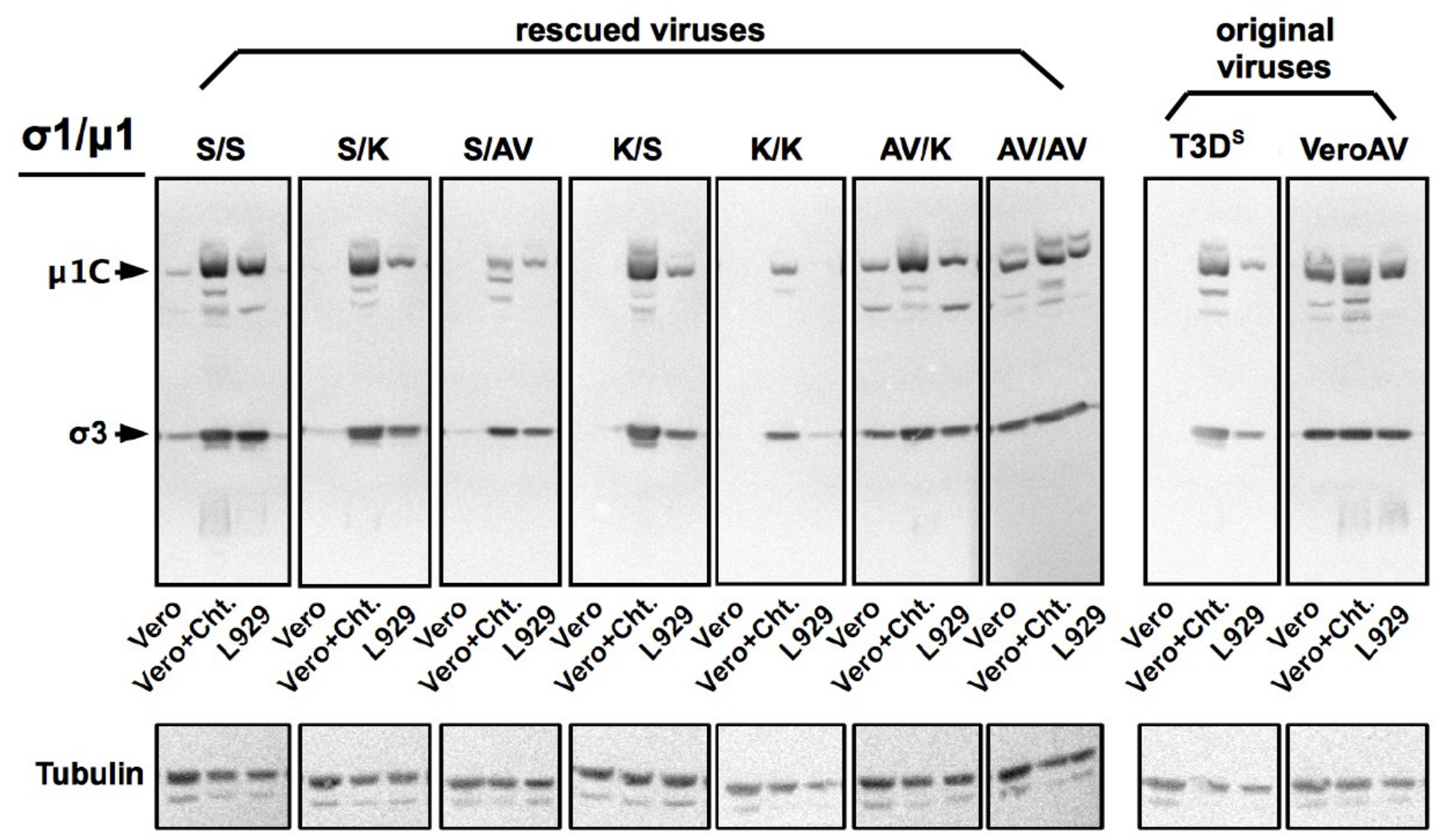


(A)

Figure 6

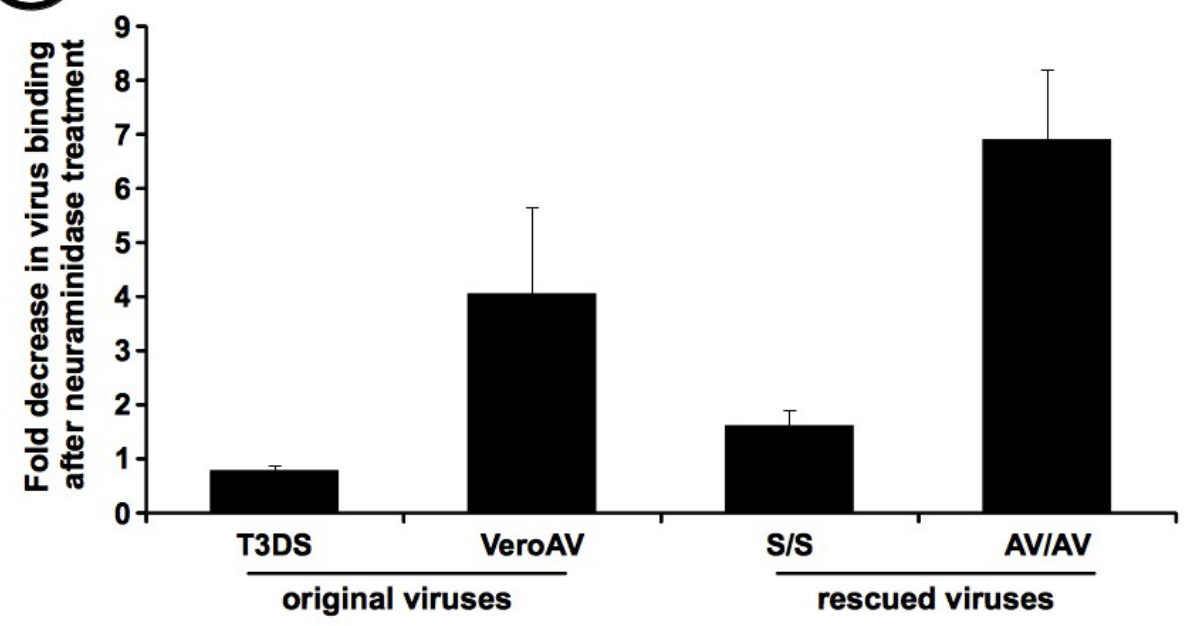

(B)
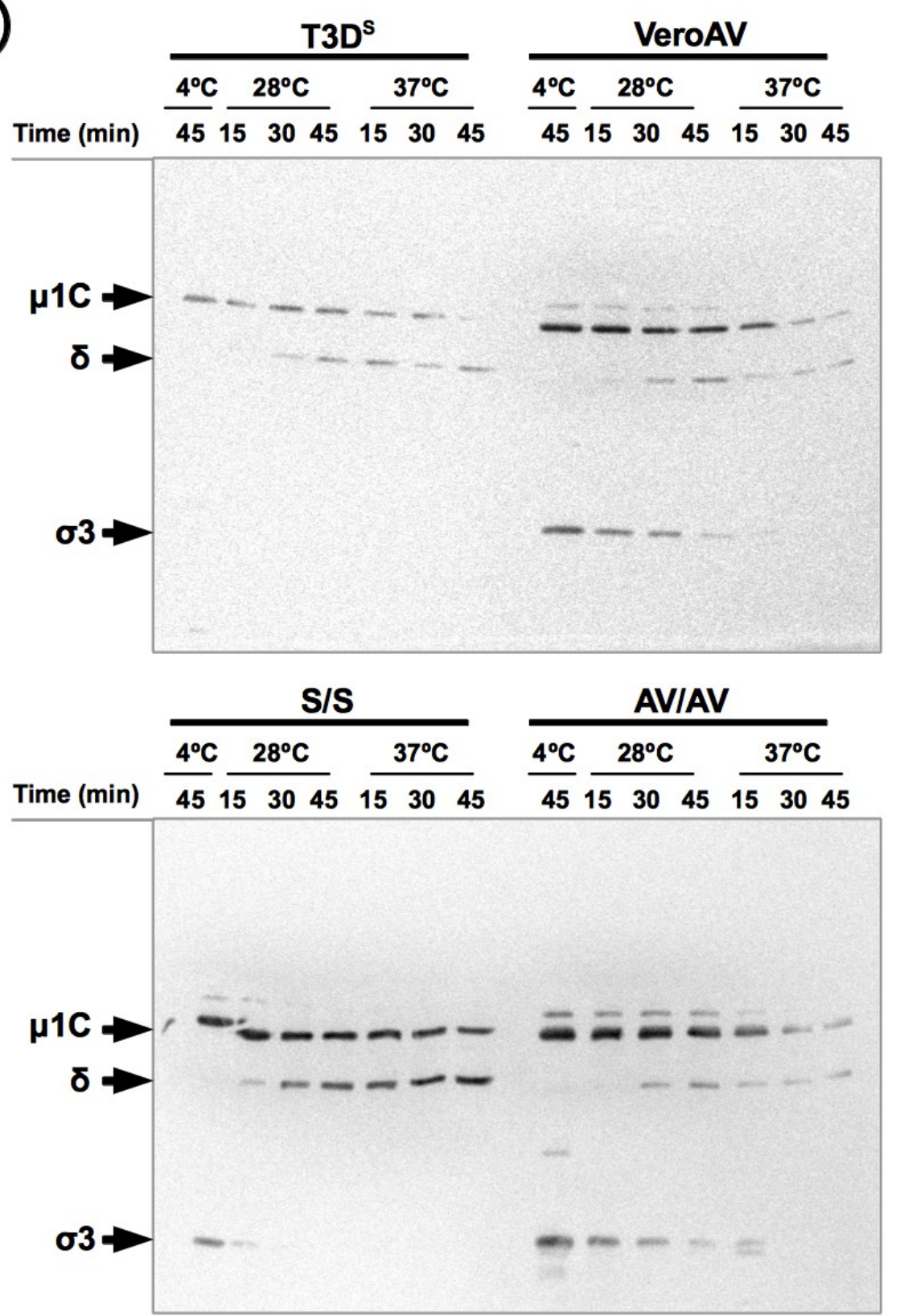
Finira 7

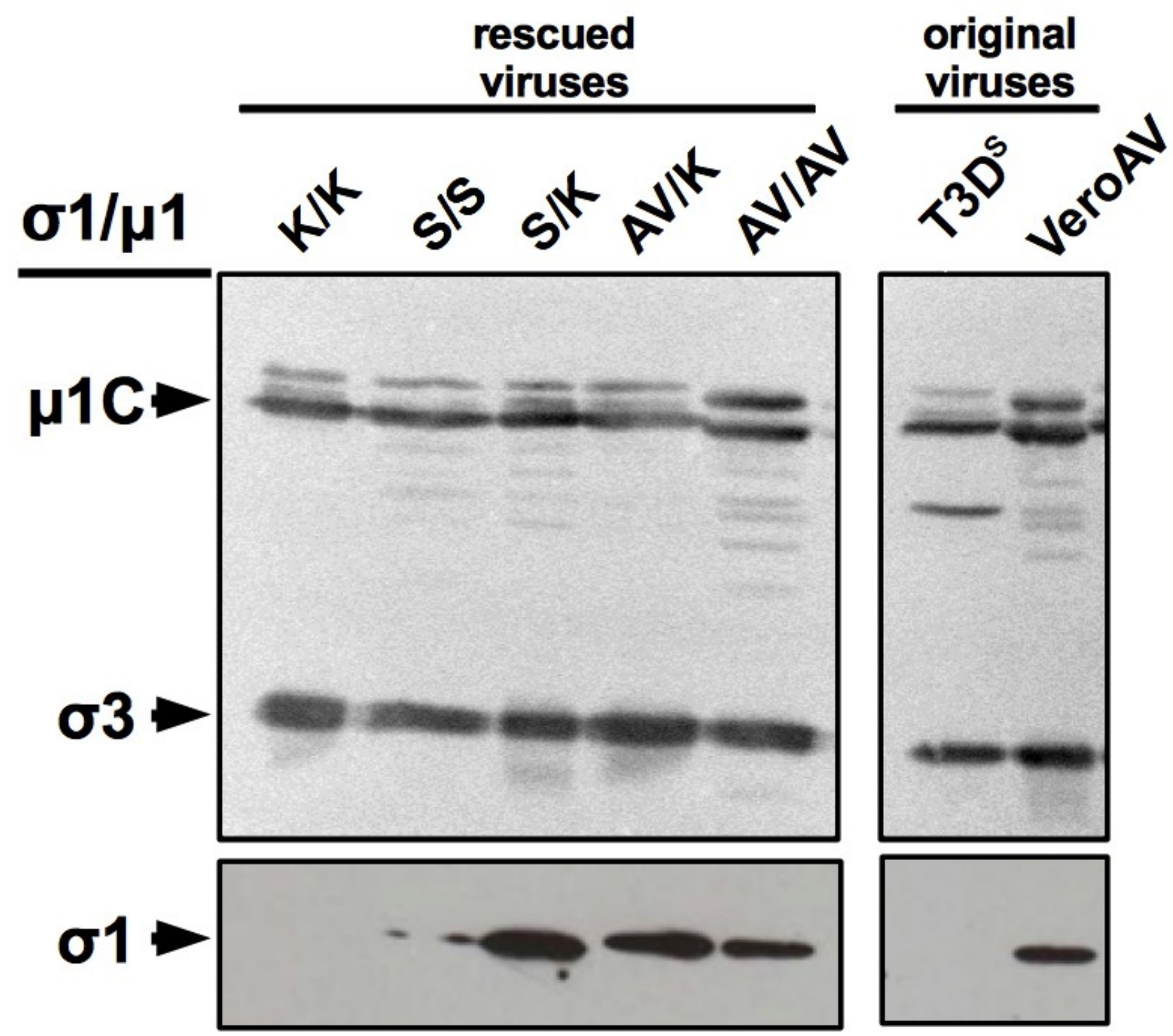


Supplementary Figure 1

\section{Dilution}

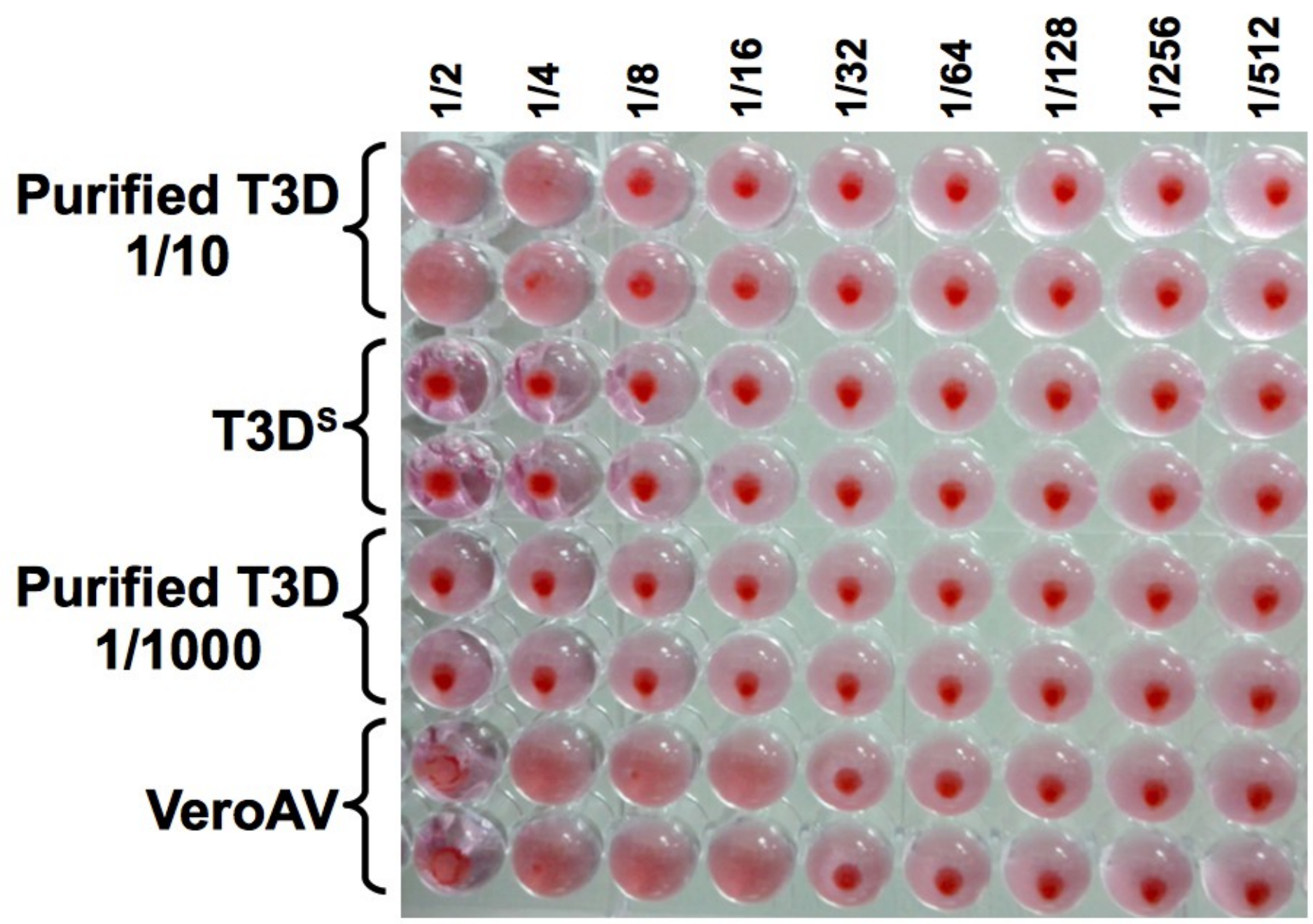

